\title{
Physical Aspects Influencing to the Production of Dry-Salted Snakeskin Gourami (Trichogaster Pectoralis)
}

\author{
NGUYEN PHUOC MINH ${ }^{1 *}$, PHAM XUAN MAI ${ }^{2}$ and NGUYEN THI VAN LINH ${ }^{3}$
}

${ }^{1}$ Faculty of Chemical Engineering and Food Technology, Nguyen Tat Thanh University, Ho Chi Minh, Vietnam.

${ }^{2}$ Can Tho University, Can Tho City, Vietnam.

${ }^{3} \mathrm{NTT}$ Hi-Tech Institute, Nguyen Tat Thanh University, Ho Chi Minh City, Vietnam.

${ }^{*}$ Corresponding author E-mail: ts.nguyenphuocminh @ gmail.com

http://dx.doi.org/10.13005/ojc/350238

(Received: November 09, 2018; Accepted: March 11, 2019)

\begin{abstract}
Snakeskin gourami (Trichogaster pectoralis) is one of the most common fish in paddy field and river in Vietnam. It lives in waters at low dissolved oxygen and high organic accumulation. It has a high meat yield and favouritely consumed as dried fish in Vietnam. Farming area of snakeskin gourami has been opened dramatically in recent years. Therefore, it's necessary to have an appropriate processing and preserving approach to accelerate its commercial value in local and international markets. Objective of the present study focused on the different aspects such as ethanol treatment to eliminate fishy ordor; addition of salt, sorbitol, as well as dry temperature that affected to to water activity (aw), microbial load (coliform, cfu/g), sensory score of dried snakeskin gourami (Trichogaster pectoralis). Shelf-life of the dried product was also evaluated during preservation. Results showed that $40 \%$ ethanol at ratio $20: 80$ for primary treatment; $2.0 \%$ of salt soaking; $1.0 \%$ of sorbitol addition; $46^{\circ} \mathrm{C}$ of drying were appropriate to maintain water activity (aw=0.65). By preserving under vacuum in PA bag, the dry-salted snakeskin gourami still extended the product shelf-life for 12 months without any deterioration.
\end{abstract}

Keywords: Snakeskin gourami, Ethanol, Salt, Sorbitol, Water activity, Shelf-life.

\section{INTRODUCTION}

Snakeskin gourami (Trichogaster pectoralis) has been considered as a valuable and suitable species for breeding in fresh and brackish water regions like Soc Trang, Bac Lieu and Ca Mau province, Vietnam. It tolerates a $\mathrm{pH}$ range between 6-8 and $22-28^{\circ} \mathrm{C}$. It lives in lowland wetlands, marshes, swamps and canals. It feeds on zooplankton, crustaceans and insect larvae ${ }^{1}$. It achieves good maturity stages after 3 months under natural environment. The living area of snakeskin gourami (Trichogaster pectoralis) from wild stocks and traditional cultures has been declined in recent years. Many hatcheries like to buy their broodstock from grow-out farms. Most snakeskin gourami grow-out farmers keep broodstock and raise their own fingerlings. Others buy fingerlings from hatcheries. Cultivation of the snakeskin gourami is ussually arranged at a stocking density of 20-40

This is an Open Access article licensed under a Creative Commons license: Attribution 4.0 International (CC- BY). Published by Oriental Scientific Publishing Company @ 2018

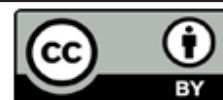


fingerling $/ \mathrm{m}^{2}$ to yield $18-22$ tonnes/ha/crop. The medium fish size at harvest ranges from 6-8 fish $/ \mathrm{kg}$, but typically $7-8 \mathrm{fish} / \mathrm{kg}$. There are various harvesting methods such as by draining based on low tides or using a cast net. Harvesting time requires $4-5$ days to complete a one ha pond. By good commercial price, farming of the snakeskin gourami offers attractive income to attract farmers.

There was little research mentioned to the processing of dried snakeskin gourami (Trichogaster pectoralis). The effect of various salt concentrations and other soluble elements on the moisture content and water activity (aw) of dried snakeskin fish was studied ${ }^{2}$. The influence of sorbitol and ethanol on the water activity and quality changes of dried snakeskin fish was examined ${ }^{3}$.

The snakeskin gourami has a high commercial meat yield and favouritely consumed as dried fish in Vietnam. Commercial farming of snakeskin gourami has been developed rapidly in recent years. Therefore, it's necessary to have an appropriate processing and preserving approach to accelerate its commercial value in local and international markets. Objective of the present study focused on different aspects such as ethanol treatment to eliminate fishy ordor; addition of salt, sorbitol, as well as dry temperature affect to water activity, microbial load, sensory score of dried snakeskin gourami (Trichogaster pectoralis of dried product.). Shelf-life of the dried product was also evaluated.

\section{MATERIALS AND METHOD}

\section{Material}

We collected snakeskin gourami (Trichogaster pectoralis) from $\mathrm{Ca}$ Mau province, Vietnam. They must be reared following BAP/ACC to ensure food safety. After collecting, they must be temporarily preserved by flake ice and conveyed to laboratory within $4 \mathrm{~h}$ for experiments. They were washed and sanitized under washing tank having $50 \mathrm{ppm}$ chlorine with a support of bubble blowing to remove foreign matters. Besides Trichogaster pectoralis we also used another material during the research such as chlorine, salt, sorbitol, PA bag. Lab utensils and equipments included digital weight balance, Rotronic, stomacher, incubator, colony counter, vacuum sealing machine.

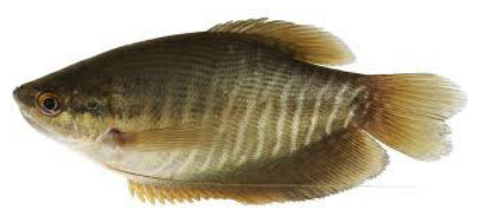

Fig. 1. Snakeskin gourami (Trichogaster pectoralis)

\section{Researching procedure}

Effect of ethanol treatment to eliminate fishy odor

Snakeskin gourami (Trichogaster pectoralis) was treated with ethanol $40 \%$ at different ratio $(0: 100$, $5: 95,10: 90,15: 85,20: 80,25: 75,30: 70$ ) to elimated fishy odor. Sensory score was used to verify the appopriate ethanol ratio.

\section{Effect of salt addition to water activity, microorganism and sensory score of the dried Trichogaster pectoralis}

Snakeskin gourami (Trichogaster pectoralis) was treated with salt at different ratio $(0 \%, 0.5 \%$, $1.0 \%, 1.5 \%, 2.0 \%, 2.5,3.0 \%$ ) to create a pleasant taste of dried product. Water activity (aw), Coliform (cfu/g) and sensory score was used to verify the appopriate salt ratio.

Effect of sorbitol addition to water activity, microorganism and sensory score of the dried Trichogaster pectoralis

Snakeskin gourami (Trichogaster pectoralis) was treated with sorbitol at different ratio $(0 \%, 0.25 \%$, $0.5 \%, 0.75 \%, 1.0 \%, 1.25 \%, 1.5 \%)$ to create a pleasant taste of dried product. Water activity (aw), Coliform (cfu/g) and sensory score was used to verify the appopriate sorbitol ratio.

Effect of drying temperature to water activity, microorganism and sensory score of the dried Trichogaster pectoralis

Snakeskin gourami (Trichogaster pectoralis) was dried in different temperature $\left(38^{\circ} \mathrm{C}, 40^{\circ} \mathrm{C}, 42^{\circ} \mathrm{C}\right.$, $44^{\circ} \mathrm{C}, 46^{\circ} \mathrm{C}, 48^{\circ} \mathrm{C}, 50^{\circ} \mathrm{C}$ ) for 3 hour. Water activity (aw), Coliform (cfu/g) and sensory score was used to verify the appopriate drying temperature.

\section{Shelf-life of the dried Trichogaster pectoralis during storage \\ Dired snakeskin gourami (Trichogaster} pectoralis) products were kept in two different packing (zipper top, vaccum) ways in PA bag and two different temperature storage conditions 
$\left(4^{\circ} \mathrm{C}, 28^{\circ} \mathrm{C}\right)$. Sensory score was evaluated in 3 months interval for 12 months.

\section{Physico-chemical and sensory analysis}

Water activity (aw) was measured by Rotronic instrument. Coliform (cfu/g) was analysed by $3 \mathrm{M}$-Petrifilm. Sensory score of Trichogaster pectoralis was assessed by a group of panelist using the 9-point hedonic scale.

\section{Statistical analysis}

The experiments were arranged in triplicate Statistical analysis was performed by the Startgraphics.

\section{RESULT \& DISCUSSION}

Effect of ethanol treatment to eliminate fishy odor

Snakeskin gourami (Trichogasterpectoralis) was treated with ethanol $40 \%$ at different ratio $(0: 100$, $5: 95,10: 90,15: 85,20: 80,25: 75,30: 70)$ to elimated fishy odor. Sensory score was used to verify the appopriate ethanol ratio. From Table 1, the fishy odor of Trichogaster pectoralis would be effectively eliminated by $40 \%$ ethanol at ratio $20: 80$ with fish.

Table 1: Effect of ethanol treatment to eliminate fishy odor of Trichogaster pectoralis

\begin{tabular}{cc}
\hline $40 \%$ ethanol ratio: fish & Sensory score \\
\hline $0 \%$ & $2.1 \pm 0.03 \mathrm{e}$ \\
$5: 95$ & $4.3 \pm 0.02 \mathrm{~d}$ \\
$10: 90$ & $5.7 \pm 0.01 \mathrm{c}$ \\
$15: 85$ & $6.6 \pm 0.02 \mathrm{~b}$ \\
$20: 80$ & $7.9 \pm 0.03 \mathrm{a}$ \\
$25: 75$ & $8.0 \pm 0.02 \mathrm{a}$ \\
$30: 70$ & $8.1 \pm 0.02 \mathrm{a}$ \\
\hline
\end{tabular}

Note: the values were expressed as the mean of three repetitions; the same characters (denoted above), the difference between them was not significant $(\alpha=5 \%)$

The influence of different salt concentrations and other soluble elements on the moisture content and water activity (aw) of dried Snakeskin fish was studied. There was a dramatic decline in water activity on the product due to the addition of ethanol, sucrose, glucose in salted fish. Corresponding to dried fish, a water activity (aw) of 0.67 can be achieved due to the use of $21 \div 24 \%$ salt, combined with $1 \%$ sucrose and $35 \mathrm{~mL}$ ethanol $/ \mathrm{kg}$ salted fish ${ }^{2}$.

Effect of salt addition to water activity, microorganism and sensory score of the dried Trichogaster pectoralis

Snakeskin gourami (Trichogaster pectoralis) was treated with salt at different ratio $(0 \%, 0.5 \%$, $1.0 \%, 1.5 \%, 2.0 \%, 2.5,3.0 \%$ ) to create a pleasant taste of dried product. Water activity (aw), Coliform $(\mathrm{cfu} / \mathrm{g})$ and sensory score was used to verify the appopriate salt ratio. From Table 2, the appropriate salt concentration should be used at $2.0 \%$ to get the lowest water activity, lowest microorganism while having the highest sensory score.

Table 2: Effect of salt addition to water activity, microorganism and sensory score of the dried Trichogaster pectoralis

\begin{tabular}{cccc}
\hline $\begin{array}{c}\text { Salt concentration } \\
(\%)\end{array}$ & $\begin{array}{c}\text { Water activity } \\
(\mathrm{aw})\end{array}$ & $\begin{array}{c}\text { Coliform } \\
\text { (cfu/g) }\end{array}$ & $\begin{array}{c}\text { Sensory } \\
\text { score }\end{array}$ \\
\hline 0 & $0.73 \pm 0.04^{\mathrm{a}}$ & $8.3 \times 102 \pm 0.02^{\mathrm{a}}$ & $3.1 \pm 0.03^{\mathrm{f}}$ \\
0.5 & $0.72 \pm 0.02^{\mathrm{ab}}$ & $4.8 \times 102 \pm 0.03^{\mathrm{b}}$ & $4.4 \pm 0.01^{\mathrm{e}}$ \\
1.0 & $0.70 \pm 0.03^{\mathrm{b}}$ & $2.7 \times 102 \pm 0.02^{\mathrm{c}}$ & $5.2 \pm 0.03^{\mathrm{d}}$ \\
1.5 & $0.69 \pm 0.01^{\mathrm{bc}}$ & $1.7 \times 102 \pm 0.01^{\mathrm{d}}$ & $6.9 \pm 0.01^{\mathrm{b}}$ \\
2.0 & $0.65 \pm 0.02^{\mathrm{c}}$ & $0.4 \times 102 \pm 0.03^{\mathrm{e}}$ & $7.8 \pm 0.04^{\mathrm{a}}$ \\
2.5 & $0.63 \pm 0.01^{\mathrm{cd}}$ & $1.1 \times 101 \pm 0.04^{\mathrm{f}}$ & $6.2 \pm 0.03^{\mathrm{bc}}$ \\
3.0 & $0.60 \pm 0.04^{\mathrm{d}}$ & $0.5 \times 101 \pm 0.02^{\mathrm{g}}$ & $6.0 \pm 0.01^{\mathrm{c}}$ \\
\hline
\end{tabular}

Note: the values were expressed as the mean of three repetitions; the same characters (denoted above), the difference between them was not significant ( $\alpha=5 \%$ ).

The preservative influence of salt is mostly based on the low water activity (aw) to prevent the growth of spoilage microorganisms ${ }^{4}$.

Effect of sorbitol addition to water activity, microorganism and sensory score of the dried Trichogaster pectoralis

Snakeskin gourami (Trichogaster pectoralis) was treated with sorbitol at different ratio $(0 \%$, $0.25 \%, 0.5 \%, 0.75 \%, 1.0 \%, 1.25 \%, 1.5 \%)$ to create a pleasant taste of dried product. Water activity (aw), Coliform (cfu/g) and sensory score was used to verify the appopriate sorbitol ratio. From Table 3 , the highest quality of dried snakeskin gourami (Trichogaster pectoralis) would be achieved by adding $1.0 \%$ of sorbitol.

Table 3: Effect of sorbitol addition to water activity, microorganism and sensory score of the dried Trichogaster pectoralis

\begin{tabular}{cccc}
\hline $\begin{array}{c}\text { Sorbitol concentration } \\
(\%)\end{array}$ & $\begin{array}{c}\text { Water activity } \\
(\mathrm{aw})\end{array}$ & $\begin{array}{c}\text { Coliform } \\
(\mathrm{cfu} / \mathrm{g})\end{array}$ & $\begin{array}{c}\text { Sensory } \\
\text { score }\end{array}$ \\
\hline 0 & $0.65 \pm 0.02^{\mathrm{a}}$ & $0.4 \times 102 \pm 0.03^{\mathrm{a}}$ & $7.8 \pm 0.04^{\mathrm{c}}$ \\
0.25 & $0.64 \pm 0.01^{\mathrm{ab}}$ & $0.3 \times 102 \pm 0.01^{\mathrm{ab}}$ & $7.9 \pm 0.01^{\mathrm{c}}$ \\
0.5 & $0.64 \pm 0.04^{\mathrm{ab}}$ & $0.2 \times 102 \pm 0.02^{\mathrm{b}}$ & $8.0 \pm 0.02^{\mathrm{bc}}$ \\
0.75 & $0.63 \pm 0.02^{\mathrm{b}}$ & $1.4 \times 101 \pm 0.04^{\mathrm{c}}$ & $8.4 \pm 0.02^{\mathrm{b}}$ \\
1.00 & $0.62 \pm 0.01^{\mathrm{bc}}$ & $1.3 \times 101 \pm 0.01^{\mathrm{cd}}$ & $8.5 \pm 0.01^{\mathrm{ab}}$ \\
1.25 & $0.62 \pm 0.00^{\mathrm{bc}}$ & $1.0 \times 101 \pm 0.00^{\mathrm{d}}$ & $8.5 \pm 0.03^{\mathrm{ab}}$ \\
1.50 & $0.60 \pm 0.04^{\mathrm{c}}$ & $0.6 \times 101 \pm 0.01^{\mathrm{e}}$ & $8.6 \pm 0.01^{\mathrm{a}}$
\end{tabular}

Note: the values were expressed as the mean of three repetitions; the same characters (denoted above), the difference between them was not significant $(\alpha=5 \%)$. 
The influence of sorbitol on moisture movement and textural change of fish and squid muscles during aging and drying processes was demonstrated. When the aging muscles were dried, slow moisture vaporization happened at the initial drying period, and the critical moisture content significantly declined with an increase in the sorbitol content of the aging muscles. The tenderness of the dried muscles was significantly limited by sorbitol aging $^{5}$. The simultaneous influences of sorbitol and ethanol on the water activity and quality changes of dried snakeskin fish were studied. The mixture of $8 \%$ sorbitol combined with $35 \mathrm{~mL}$ ethanol/kg salted fish were recommended as a critical value to the water activity changes of product $(a w=0.67)$. By application of this procedure, the dried fish quality was stable until 5 weeks of storage ${ }^{3}$. The influence of sorbitol would create the decrease of drying time and the reduction of the excess tenderness of dried fish ${ }^{6}$.

Effect of drying temperature to water activity, microorganism and sensory score of the dried Trichogaster pectoralis

Snakeskin gourami (Trichogaster pectoralis) was dried in different temperature $\left(38^{\circ} \mathrm{C}, 40^{\circ} \mathrm{C}, 42^{\circ} \mathrm{C}\right.$, $44^{\circ} \mathrm{C}, 46^{\circ} \mathrm{C}, 48^{\circ} \mathrm{C}, 50^{\circ} \mathrm{C}$ ) for 3 hours. Water activity (aw), Coliform (cfu/g) and sensory score was used to

Table 4: Effect of drying temperature to the dried Trichogaster pectoralis

\begin{tabular}{cccc}
\hline $\begin{array}{c}\text { Drying } \\
\text { temperature }\end{array}$ & $\begin{array}{c}\text { Water activity } \\
(\mathrm{aw})\end{array}$ & $\begin{array}{c}\text { Coliform } \\
\text { (cfu/g) }\end{array}$ & $\begin{array}{c}\text { Sensory } \\
\text { score }\end{array}$ \\
\hline $38^{\circ} \mathrm{C}$ & $0.65 \pm 0.03^{\mathrm{a}}$ & $2.0 \times 101 \pm 0.03^{\mathrm{a}}$ & $7.0 \pm 0.04^{\mathrm{d}}$ \\
$40^{\circ} \mathrm{C}$ & $0.64 \pm 0.00^{\mathrm{ab}}$ & $1.8 \times 101 \pm 0.01^{\mathrm{ab}}$ & $7.3 \pm 0.02^{\mathrm{cd}}$ \\
$42^{\circ} \mathrm{C}$ & $0.64 \pm 0.04^{\mathrm{ab}}$ & $1.6 \times 101 \pm 0.02^{\mathrm{b}}$ & $7.5 \pm 0.03^{\mathrm{c}}$ \\
$44^{\circ} \mathrm{C}$ & $0.63 \pm 0.02^{\mathrm{b}}$ & $1.4 \times 101 \pm 0.04^{\mathrm{bc}}$ & $8.2 \pm 0.01^{\mathrm{ab}}$ \\
$46^{\circ} \mathrm{C}$ & $0.62 \pm 0.01^{\mathrm{bc}}$ & $1.3 \times 101 \pm 0.01^{\mathrm{c}}$ & $8.5 \pm 0.01^{\mathrm{a}}$ \\
$48^{\circ} \mathrm{C}$ & $0.60 \pm 0.03^{\mathrm{c}}$ & $1.1 \times 101 \pm 0.02^{\mathrm{cd}}$ & $8.1 \pm 0.00^{\mathrm{b}}$ \\
$50^{\circ} \mathrm{C}$ & $0.60 \pm 0.00^{\mathrm{c}}$ & $0.8 \times 101 \pm 0.03^{\mathrm{d}}$ & $8.0 \pm 0.04^{\mathrm{b}}$ \\
\hline
\end{tabular}

Note: the values were expressed as the mean of three repetitions; the same characters (denoted above), the difference between them was not significant $(\alpha=5 \%)$. verify the appopriate drying temperature. The drying process should be conducted at $46^{\circ} \mathrm{C}$ to maintained the lowest water activity, microorganism as well as the highest sensory score.

Salting and drying was one of the most effective ways of food preservation. For dried fish, salt was not enough as well as the temperature does not fit in the process of processing, preservation and distribution was the cause of boosting the growth of micro-organisms. To minimize the risk of poisoning, salt in the liquid phase in fish products must reach at least $3.5 \%{ }^{2}$. The law of Raoult to explain the dependence of water activity (aw) on different levels of soluble substances and moisture content of the food system. There was a correlation of water activity in dried fish products to different levels of salt concentration. The concentration of salt concentration from $15 \%$ to $24 \%$ or salt time must be long enough ${ }^{7}$. The influences of 4 different temperatures and 4 different pre-treatment methods on the drying rate and the quality of catfish were examined ${ }^{8}$.

\section{Shelf-life of the dried Trichogaster pectoralis during storage}

Oid oxidation is the major obstacles in the salted fish. Oil oxidation creates negative effect to taste, odor and color of salted fish. Vacuum packaging can be utilized as one method to maintain the stability and quality of a salted fish. Vacuum packaging is an effective approach to delay the oil oxidation by eliminating oxygen molecule. ${ }^{9}$

Dry-salted snakeskin gourami (Trichogaster pectoralis) products were kept in two different packing (zipper top, vaccum) ways in PA bag and two different temperature storage conditions $\left(4^{\circ} \mathrm{C}, 28^{\circ} \mathrm{C}\right)$. Sensory score was evaluated in 3 months interval for 12 months. Results from Table 5 showed that the dry-salted snakeskin gourami (Trichogaster pectoralis) still mainted quality during 12 months of storage.

Table 5: Shelf-life (sensory score) of the dried Trichogaster pectoralis during storage

\begin{tabular}{|c|c|c|c|c|}
\hline \multirow[t]{2}{*}{$\begin{array}{l}\text { Storage time } \\
\text { (month) }\end{array}$} & \multicolumn{2}{|c|}{$\begin{array}{l}\text { Dried Trichogaster pectoralis by the storage } \\
\text { temperature }\left({ }^{\circ} \mathrm{C}\right) \text { kept in PA (zipper top) }\end{array}$} & \multicolumn{2}{|c|}{$\begin{array}{l}\text { Dried Trichogaster pectoralis by the storage } \\
\text { temperature }\left({ }^{\circ} \mathrm{C}\right) \text { kept in PA (vaccum) }\end{array}$} \\
\hline & $4^{\circ} \mathrm{C}$ & $28^{\circ} \mathrm{C}$ & $4^{\circ} \mathrm{C}$ & $28^{\circ} \mathrm{C}$ \\
\hline 0 & $8.5 \pm 0.01^{a}$ & $8.5 \pm 0.01^{\mathrm{a}}$ & $8.5 \pm 0.01^{a}$ & $8.5 \pm 0.01^{a}$ \\
\hline 3 & $8.3 \pm 0.01^{\mathrm{ab}}$ & $8.2 \pm 0.00^{\mathrm{ab}}$ & $8.5 \pm 0.01^{a}$ & $8.4 \pm 0.03^{\mathrm{ab}}$ \\
\hline 6 & $8.2 \pm 0.01^{b}$ & $8.0 \pm 0.04^{b}$ & $8.4 \pm 0.02^{a b}$ & $8.2 \pm 0.02^{b}$ \\
\hline 9 & $8.0 \pm 0.01^{b c}$ & $7.9 \pm 0.02^{\mathrm{bc}}$ & $8.4 \pm 0.01^{a b}$ & $8.0 \pm 0.01^{b c}$ \\
\hline 12 & $7.7 \pm 0.01^{c}$ & $7.5 \pm 0.03^{c}$ & $8.3 \pm 0.00^{b}$ & $7.9 \pm 0.00^{c}$ \\
\hline
\end{tabular}

Note: the values were expressed as the mean of three repetitions; the same characters (denoted above), the difference between them was not significant $(\alpha=5 \%)$. 
The stability of lakerda in stretch film and vacuum package preserved for 56 days at $4 \pm 2^{\circ} \mathrm{C}$ after the ripening and dry salting was compared. They showed that vacuum packaging is an useful way to maintain chemical and microbial characteristics of drysalted lakerda kept at $4 \pm 2^{\circ} \mathrm{C}$ during the $56^{\text {th }}$ days ${ }^{10}$.

\section{CONCLUSION}

Snakeskin gourami (Trichogasterpectoralis) lives in different areas of river, paddy field and wamp to avoid predation from birds and other fishes. The intensive farming of snakeskin gourami culture creates large quantity, so it's necessary to commercial processing and storage of this species.
The salting, fermenting, marinating, smoking and drying are effective approaches to preserve fish. Salting, drying and packaging can be considered as an appropriate strategy to maitained its product shelf-life. From this present study, vacuum packaging significantly increased shelf life of dry-salted snakeskin gourami (Trichogaster pectoralis).

\section{ACKNOWLEDGEMENT}

We acknowledge the resources and financial support for the study was provided by Nguyen Tat Thanh University, Vietnam.

\section{CONFLICT OF INTEREST}

Conflict of interest declared none.

\section{REFERENCES}

1. Hojatollah Jafaryan; Javad Sahandi; Javad Bagheri Dorbadam. Growth and length-weight relationships of Trichopodus trichopterus (Pallas, 1770) fed a supplemented diet with different concentrations of probiotic. Croatian Journal of Fisheries., 2014, 72, 118- 122.

2. Nguyen Van Muoi; Tran Thanh Truc. Effect of different solutes on water activity of dried Snakeskin fish (Trichogaster Pectoralis Regan). Can Tho University Scientific Journal., 2008, 10, 151-160.

3. Tran Thanh Truc; Do Thi Khanh Doan; Nguyen Van Muoi. Effect of sorbitol and ethanol on the aw and quality changes of dried snakeskin fish. Can Tho University Scientific Journal., 2009, 11, 317-326.

4. Leroi, F.; Joffraud, J. J. Salt and smoke simultaneously affect chemical and sensory quality of cold-smoked salmon durin $5^{\circ} \mathrm{C}$ storage predicted using factorial design. Journal of Food Protection., 2000, 63, 1222-1227.

5. Zensuke Iseya; Tomokazu Kubo; Hiroki Saeki. Effect of sorbitol on moisture transportation and textural change of fish and squid meats during curing and drying processes. Fisheries
Science., 2008, 66, 1144-1149.

6. Kubo, T. and Saeki, H. Role of sorbitol in manufacturing dried seafood from heated squid meat. Fisheries Science., 2001, 67, $524 \div 529$.

7. Jittinandana, S.; Kenney, P.B.; Slider, S.D.; and Kiser, R.A. Effect of brine concentration and brining time on quality of smoked rainbow trout fillets. Journal of Food Science., 2002, 67, 2095-2099.

8. Michael Ayodele Omodara; Adesoji Matthew Olaniyan. Effects of pre-treatments and drying temperatures on drying rate and quality of African catfish (Clarias gariepinus). Journal of Biology, Agriculture and Healthcare., 2012, 2, 1-11.

9. Taheri, S.; Motallebi, A.A. Influence of vauum packaging and long term storage on some quality parameters of cobia (Rachycentroncanadum) fillets during frozen storage. American-Eurasian J. Agric. \& Environ Sci., 2012, 12, 541-547.

10. Kocatepe, D.; Turan, H.; Altan, C.O.; Göknar, $G$. Effect of the vacuum packaging on the shelf life of Lakerda. Int J Food Sci Nutr Diet., 2014, 3, 157-159. 